\title{
Synthesis and characterization of ruthenium (II) complexes with new Schiff base ligand from the reaction of 4-(aminomethyl)phenol with picolinaldehyde
}

\author{
Arif AKTAŞ ${ }^{1}$ Esin ISPPIR*1 \\ ${ }^{1}$ Department of Chemistry, Kahramanmaraş Sütçü İmam University, Kahramanmaraş, 46050-9, Turkey
}

\begin{abstract}
The Schiff base ligand containing N,N donor atoms, (E)-4-(( pyridin-2ylmethylene)amino)methyl)phenol $\left(L^{1} H\right)$ (Fig. 1), and its $\mathrm{Ru}(\mathrm{II})$ complex have been prepared. The ligand and its complex have been characterized by elemental analyses, IR spectra, UV-Visible spectroscopy, ${ }^{1} \mathrm{H}$ and ${ }^{13} \mathrm{C}$ NMR spectra and magnetic susceptibility measurements. The analytical data show that the metal to ligand ratio in the $\mathrm{L}^{1} \mathrm{H}$ complexes is $1: 1$.
\end{abstract}

Keywords: Schiff Base; Ru(II) complexes, characterization

\section{4-(aminometil)fenol ve pikolinaldehitten sentezlenen Schiff bazı ligandı ve Ru(II) kompleksinin sentez ve karakterizasyonu}

ÖZET: N,N donor atomlu Schiff bazı ligandı ve onun rutenyum (II) kompleksi sentezlenmiștir. Ligand ve kompleksin yapıları IR, UV-Visible spektroskopisi, ${ }^{1} \mathrm{H}$ ve ${ }^{13} \mathrm{C}$ NMR spektroskopisi, elementel analiz magnetik süssebtibilite yöntemleri ile karakterize edilmiştir. Analitik veriler kompleks yapısında metal ligand oranının 1:1 olduğunu göstermiştir.

Anahtar Kelimeler: Schiff bazı, Ru(II) kompleksleri, karakterizasyon

\section{INTRODUCTION}

Among the various ligands, Schiff base ligands have significant importance because Schiff base ligands are potentially capable of forming stable complexes with metal ions [1]. By attaching donor atoms of Schiff bases, they can coordinate various metals and stabilize them in different oxidation states; such complexes are used as catalysts in many important processes [2, 3]. Schiff base complexes containing different central metal atoms such as $\mathrm{Cu}, \mathrm{Ni}$, Co and Pd have been studied in great detail for their various crystallographic features, enzymatic reactions, steric effects, structure-redox relationships, mesogenic characteristics, catalysis, magnetic properties and their important role in the understanding of the coordination chemistry of transition metal ions. In some Schiff base metal chelates, it has been show that minor changes in the structure of the ligands containing hard/soft donor atoms, e.g., nitrogen, sulfur and/or oxygen markedly affected the activity of these compounds [4-5]. Metal complexes of Schiff bases have been extensively studied at scientific applications as catalysts due to their attractive chemical and physical properties.

Complex formation studies of ruthenium with azo/azoimine ligands and their usage at transfer hydrogenation reaction, metal-carbon bond formation and catalytic transformations have been ongoing [6]. The ruthenium complexes formed by different types of ligands have significant importance. To design the new types of ruthenium (II) Schiff base complexes bearing oxygen and nitrogen donor atoms have importance due to their potential catalytic activities [7]. During recent years, half-sandwich ( $\eta^{6}$-arene)ruthenium (II) complexes draw attention very much and proceed to be the subject of intense research in the field of organometallic chemistry emphatically [8-9].

Due to the importance of the various properties of Schiff base metal complexes, we herein reported the synthesis and characterization of $\mathrm{L}^{1} \mathrm{H}$ and its $\mathrm{Ru}(\mathrm{II})$ metal complex.

Ligand and complex structures were confirmed by, elemental analysis, FTIR, ${ }^{1} \mathrm{H}-,{ }^{13} \mathrm{C}-\mathrm{NMR}$, UVVisible spectroscopy and elemental analyses. The 
analytical data shows that the ratio of metal to ligand in the mononuclear Schiff Base complexes is 1:1.

\section{EXPERIMENTAL}

\subsection{Materials and measurements}

Reagents and solvents were purchased from chemical suppliers and purified to match the reported physical and spectroscopic data. The solvents were carefully dried using standard methods. Melting points were determined with an Electrothermal 9200 apparatus. Elemental analyses $(\mathrm{C}, \mathrm{H}, \mathrm{N})$ were performed using a Carlo Erba 1106 elemental analyser. Infrared spectra were obtained using $\mathrm{KBr}$ discs (4000-400 $\mathrm{cm}^{-1}$ ) on a Shimadzu 8300 FTIR spectrophotometer. The electronic spectra in the 200-900 nm range were obtained using DMF on a Hithachi U-3900 spectrophotometer. ${ }^{1} \mathrm{H}$ and ${ }^{13} \mathrm{C}$ NMR spectra were recorded on a Varian AS- $400 \mathrm{MHz}$ instrument. TMS was used as internal standard and deuterated DMSO as solvent. Magnetic measurements were carried out by the Gouy method using $\mathrm{Hg}\left[\mathrm{Co}(\mathrm{SCN})_{4}\right]$ as calibrant.

\subsection{Synthesis of (E)-4-(((pyridin-2- ylmethylene)amino)methyl)phenol $\left(\mathrm{L}^{1} \mathrm{H}\right)$}

(E)-4-(((pyridin-2-ylmethylene)amino)methyl)

Phenol $1\left(\mathrm{~L}^{1} \mathrm{H}\right)$ (Figure 1$)$ was synthesized as follow; 10 mmol (1.23 g) 4-(aminomethyl)phenol and $10 \mathrm{mmol}$ $(1.07 \mathrm{~g})$ of picolinaldehyde were condensed by refluxing in $70 \mathrm{~cm}^{3}$ of absolute ethanol for $3 \mathrm{~h}$. The solution was left at room temperature. (E)-4-(((pyridin2-ylmethylene)amino)methyl)

phenol was obtained as brown micro crystals; the micro crystals were filtered off, washed with $10 \mathrm{~cm}^{3}$ of absolute ethanol and then recrystallized from DMF. Mp: $130^{\circ} \mathrm{C}$. ${ }^{1} \mathrm{H}$ NMR $\left(400 \mathrm{MHz}, \mathrm{CDCl}_{3}\right) \delta 10.02(\mathrm{~s}, 1 \mathrm{H})$, 8.64 (d, $J=64.7 \mathrm{~Hz}, 1 \mathrm{H}), 8.35$ (s, 1H), 7.99 (s, 1H), 7.69 (s, 1H), 7.28 (s, 1H), 6.98 (s, 2H), 6.60 (s, 2H), 4.71 (s, 2H). ${ }^{13} \mathrm{C}$ NMR (101 MHz, $\left.\mathrm{CDCl}_{3}\right) \delta 161.92$, 155.84, 153.96, 148.89, 137.07, 129.84, 128.70, 125.00, 121.48, 115.58, 63.81. FT-IR (KBr, $\left.\mathrm{cm}^{-1}\right)$ : 3027, 28762789, 1639. Anal. Cald. For: $\left[\mathrm{C}_{13} \mathrm{H}_{12} \mathrm{~N}_{2} \mathrm{O}\right.$ ], C: 73.56, $\mathrm{H}$ : 5.70, N:13.20. Found: C: 73.29, H: 5.59, N: 13.01. UVVis. $\left(\lambda_{\max }, \mathrm{nm}\right)$ in MetOH: 255, 273, 280, 391.

\subsection{General procedure for the synthesis of Ru(II) metal complex}

Dichloro( $p$-cymene)ruthenium(II) dimer (0.28 g,0.47 mmol) was added to the solution of E)-4(((pyridin-2-ylmethylene)amino)methyl) phenol 2 (0.2 $\mathrm{g}, 0.94 \mathrm{mmol})$ in methanol $(10 \mathrm{ml})$ in one portion and refluxed for $6 \mathrm{~h}$ at nitrogen atmosphere in a schlenk tube. The precipitate was filtered and rinsed petroleum ether $(20 \mathrm{~mL})$ and diethyl ether $(20 \mathrm{~mL})$. The complex 2 was obtained as brown solid. The Ru(II) complex is soluble in solvents such as EtOH and MetOH. Mp: $190^{\circ} \mathrm{C}$. ${ }^{1} \mathrm{H}$ NMR (300 MHz, DMSO) $\delta 9.95(\mathrm{~s}, 1 \mathrm{H})$, 9.60 (d, $J=4.5 \mathrm{~Hz}, 1 \mathrm{H}), 8.37$ (s, 1H), 8.23 (s, 2H), 7.78 (s, 2H), 7.28 (d, $J=7.8 \mathrm{~Hz}, 1 \mathrm{H}), 6.91(\mathrm{~d}, J=7.8 \mathrm{~Hz}$, $2 \mathrm{H}), 6.31$ (d, $J=5.7 \mathrm{~Hz}, 2 \mathrm{H}), 6.08$ (d, $J=5.7 \mathrm{~Hz}, 1 \mathrm{H})$, 5.92 (dd, $J=12.0,5.8 \mathrm{~Hz}, 1 \mathrm{H}), 5.65$ (d, $J=16.1 \mathrm{~Hz}$, 2H), 5.30 (d, $J=16.1 \mathrm{~Hz}, 1 \mathrm{H}), 2.56$ (m, 1H), 2.14 (s, $1 \mathrm{H}), 1.01$ (d, $J=6.5 \mathrm{~Hz}, 3 \mathrm{H}), 0.91$ (d, $J=6.5 \mathrm{~Hz}, 6 \mathrm{H})$. FT-IR (KBr, $\left.\mathrm{cm}^{-1}\right)$ : 3037, 2866-2785, 1626. Anal. Cald. For: $\left[\mathrm{C}_{23} \mathrm{H}_{26} \mathrm{Cl}_{2} \mathrm{~N}_{2} \mathrm{ORu}\right.$ ], C: 53.28, $\mathrm{H}: 5.05, \mathrm{~N}: 5.40$. Found: C: 53.16, H: 5.09, N: 5.31. UV-Vis. $\left(\lambda_{\max }, \mathrm{nm}\right)$ in DMF: 274, 328, 363, 396, 404. $\mu_{\mathrm{eff}}, \mathrm{BM:}$ Diamagnetic.

\section{RESULT and DISCUSSION}

\subsection{Synthesis of the compounds}

The $\mathrm{L}^{1} \mathrm{H}$ ligand, was prepared by the reaction of 4-(aminomethyl)phenol with picolinaldehyde, (1:1 molar ratio) in EtOH as shown in Figure 1. The level of the purity of the ligand was checked by T.L.C. on silica gel-coated plates. Beside this the Ruthenium (II) complex of $\mathrm{L}^{1} \mathrm{H}$ was prepared. The ligand is stable at room temperature and soluble in common organic solvents such as EtOH, $\mathrm{MeOH}, \mathrm{DMF}$ and $\mathrm{CH}_{2} \mathrm{Cl}_{2}$. The complex is also stable at room temperature.

In the ligand FTIR spectra, $\mathrm{L}^{1} \mathrm{H}$ exhibit $\mathrm{OH}$ band at $3420 \mathrm{~cm}^{-1}$ that are assignable to $v(\mathrm{OH})$. The bands at $2876-2789 \mathrm{~cm}^{-1}$ can be assigned to $v(\mathrm{Ar}-\mathrm{CH})$ [10-11]. The band at $1639 \mathrm{~cm}^{-1}$ is due to the vibration of the azomethine group in the ligand.

The electronic absorption spectral data for $\mathrm{L}^{1} \mathrm{H}$ ligand was obtained in $\mathrm{MetOH}$ solution at room temperature. There are absorption bands between 404 and $255 \mathrm{~nm}$ for the ligand and its metal complex at the UV-visible spectra. The band at $\lambda_{\max } 390 \mathrm{~nm}$ was assigned to $n \rightarrow \pi^{*}$ transitions of the azomethine groups in the $\mathrm{L}^{1} \mathrm{H}$ ligand. In the spectra of the complex, the bands of the azomethine $n \rightarrow \pi^{*}$ transitions shifted to lower frequencies indicating the involment of the imine nitrogen atom with the metal ion.

In order to better understand the structure of the ligand, ${ }^{1} \mathrm{H}$ and ${ }^{13} \mathrm{C}$ NMR spectral data in $\mathrm{CDCl}_{3}$ as solvent are given in Figure 2 and exhibit all expected signals.

The ${ }^{1} \mathrm{H}$ NMR spectra of the ligand exhibit singlet signals in the $10.02 \mathrm{ppm}$ and $8.64 \mathrm{ppm}$ which are attributed to the $\mathrm{OH}$ and azomethine group protons, respectively [1]. In the spectra of the $\mathrm{Ru}(\mathrm{II})$ complex, the singlets which are attributed to the $\mathrm{OH}$ and azomethine groups, are seen in the 9.95 and $9.60 \mathrm{ppm}$ as singlet signals. The differecnce at these signals can be 
originating from coordination of the ligand to the metal ion via the azomethine nitrogen.<smiles>NCc1ccc(O)cc1</smiles><smiles>Oc1ccc(C/N=C/c2ccccn2)cc1</smiles>

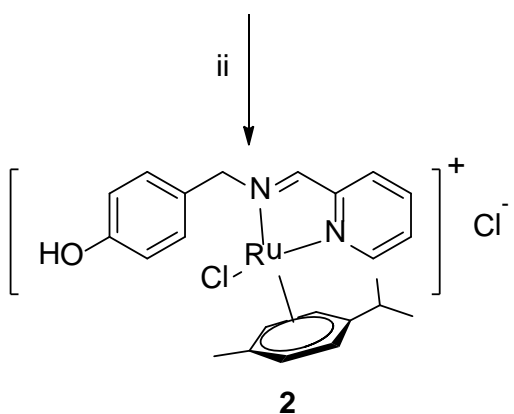

(i) Ethanol, reflux, 3 h; (ii) $\left[\mathrm{RuCl}_{2} \text { (p-cymene) }\right]_{2}, \mathrm{MeOH}, 50{ }^{\circ} \mathrm{C}, 12 \mathrm{~h}$;

Figure 1. General sythesis of $\mathrm{L}^{1} \mathrm{H}$ ligand and its $\mathrm{Ru}(\mathrm{II})$ complex.

In the $\mathrm{L}^{1} \mathrm{H}$ spectrum, singlet signal at 4.71 and signals at 8.35-6.60 ppm may be assigned to aliphatic $\mathrm{CH}_{2}$ prothons and aromatic ring protons respectively. The ${ }^{1} \mathrm{H}$ NMR spectrum of $\mathrm{L}^{1} \mathrm{H}$ is taken as a represantive example and shown in Figure 2. Unlike the ligand, in the $\mathrm{Ru}(\mathrm{II})$ complex spectrum, the dublet signals at 1.01 and $0.91 \mathrm{ppm}$ can be attributed to the $\mathrm{CH}_{3}$ prothons that originated from $p$-cymene molecule.

The ${ }^{13} \mathrm{C}$ NMR spectra of the ligands exhibit singlet signals at $161.92 \mathrm{ppm}$ which can be assigned to the azomethine group carbon atoms [12]. The signals due to the carbon atoms of aromatic ring are observed in the 115.58-155.84 ppm range.
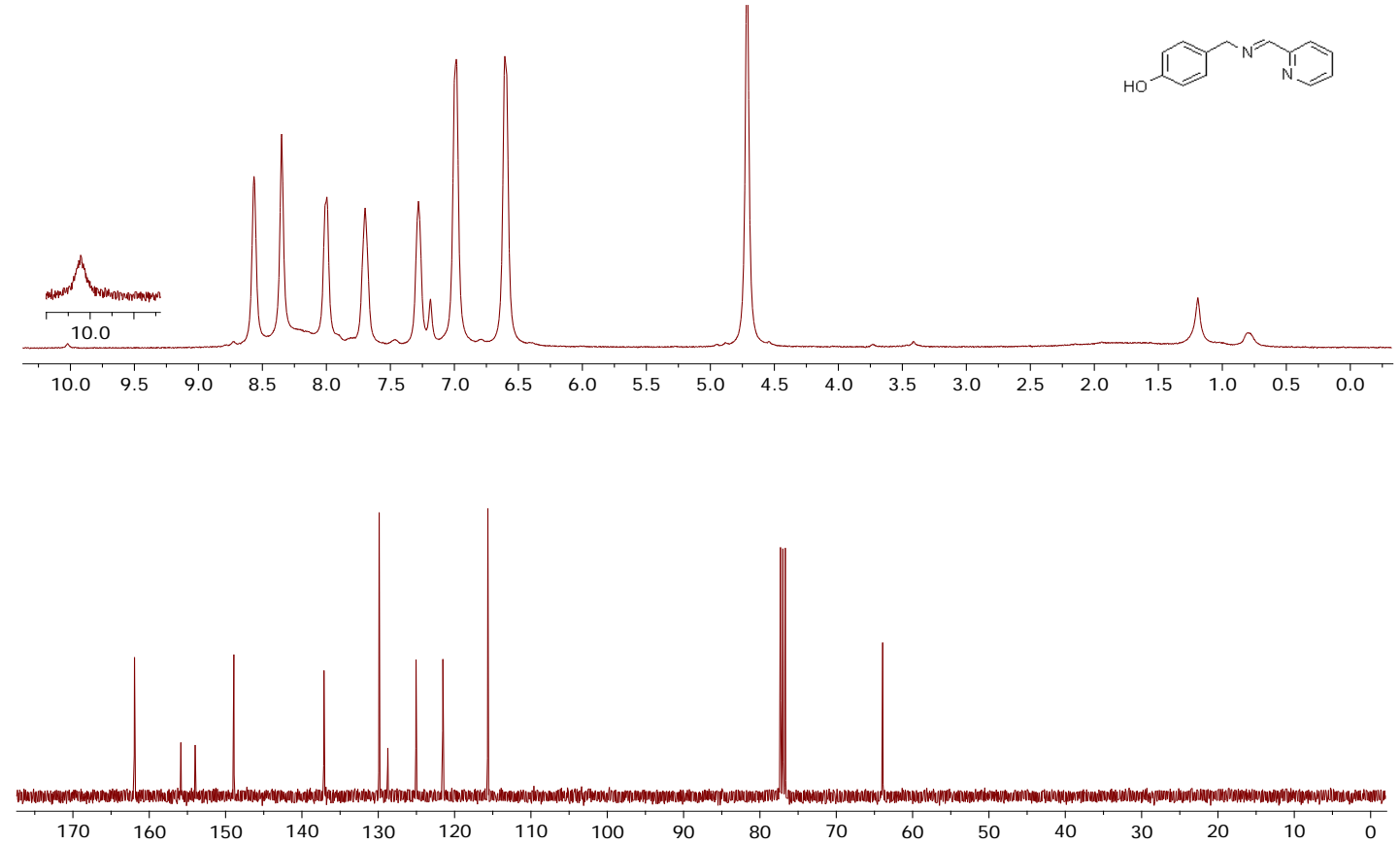

Figure 2. ${ }^{1} \mathrm{H}$ and ${ }^{13} \mathrm{C}$ NMR spectra of $\mathrm{L}^{1} \mathrm{H}$ ligand. 


\section{CONCLUSIONS}

The Schiff base ligand containing N,N donor atoms, (E)-4-(( pyridin-2ylmethylene)amino)methyl)phenol $\left(L^{1} H\right)$ (Fig. 1) and its $\mathrm{Ru}$ (II) complex have been prepared in good yields. The ligand and their complex have been characterized by elemental analyses, IR spectra, UV-Visible spectroscopy, ${ }^{1} \mathrm{H}$ and ${ }^{13} \mathrm{C}$ NMR spectra and magnetic susceptibility measurements. The analytical data show that the metal to ligand ratio in the $\mathrm{L}^{1} \mathrm{H}$ complexes is $1: 1$.

\section{ACKNOWLEDGEMENTS}

This work was financially supported by the Unit of Coordination of Scientific Research Projects, Kahramanmaraş Sütçü Imam University, Kahramanmaraş, Turkey (Project no: 2013/5-14 M).

\section{REFERENCES}

[1]. Ispir E. The synthesis, characterization, electrochemical character, catalytic and antimicrobial activity of novel, azo-containing Schiff bases and their metal complexes. Dyes Pigments. 2009; 82(1):13-9.

[2]. Atabey, H., Findik, E., Sari, H., Ceylan, M., "Comparison of chelating ability of NO-, NS-, ONS-, and ONO-type Schiff base derivatives and their stability constants of Bis-complexes with copper(II)”, Turk J Chem., 2014, 38(1), 109.

[3]. Huang, D. X., Wang, C. X., Song, Y. B., "Immobilized complexes of the salen Schiff's base with metal as oxidation catalysts”, Russ J Gen Chem., 2013, 83(12), 2361.

[4]. Khandar. A. A.; Nejati, K. Synthesis And Characterization of a Series of Copper(II) Complexes With Azo-linked Salicylaldimine Schiff Base Ligands. Crystal Structure of Cu5PHAZOSALTN.

[5]. $\mathrm{CHCl}_{3}$. Polyhedron. 2000, 19, 607-613.

[6]. Tümer, M.; Çelik, C.; Köksal, H.; and Serin, S. Transition Metal Complexes of Bidentate Schiff Base Ligands. Trans. Met. Chem. 1999, 24, 525.

[7]. J.L. Pratihar, S. Bhaduri, P. Pattanayak, D. Patra, S. Chattopadhyay, Reactions of 2-(arylazo)aniline with ruthenium substrates: Isolation, characterizations and reactivities of delocalized diazoketiminato and orthometallated $\mathrm{Ru}(\mathrm{II})$ chelates, J Organomet Chem, 2009, 694,34013408.

[8]. R.N. Prabhu, R. Ramesh, Synthesis, structural characterization, electrochemistry and catalytic transfer hydrogenation of ruthenium(II) carbonyl complexes containing tridentate benzoylhydrazone ligands, J Organomet Chem, 2012, 718, 43-51.

[9]. R.K. Rath, M. Nethaji, A.R. Chakravarty, Synthesis, crystal structure and catalytic properties of (p-cymene)ruthenium(II) azophenol complexes: azophenyl to azophenol conversion by oxygen insertion to a ruthenium $\mathrm{C}$ carbon bond, J Organomet Chem, 2001, 633, 79-84.

[10]. R.K. Rath, M. Nethaji, A.R. Chakravarty, Transfer hydrogenation of acetophenone promoted by (arene)ruthenium(II) reduced Schiff base complexes: an X-ray structure of [( cymene)RuCl(OC6H4-2-CH2NHC6H4-p-Me)], Polyhedron, 2001, 20, 2735-2739.

[11]. Sanmartin, J.; Bermejo,M. R.; Gariç-Deibe, A. M.; Maneiro, M.; Large, C.; Costa-Filho, A. J. Monoand Polynuclear Complexes of $\mathrm{Fe}(\mathrm{II}), \mathrm{Co}(\mathrm{II})$, $\mathrm{Ni}(\mathrm{II}), \mathrm{Cu}(\mathrm{II}), \mathrm{Zn}(\mathrm{II})$ and $\mathrm{Cd}(\mathrm{II})$ with N,N-Bis(3hydroxysalicylidene)-1,3-diamino-2-propanol. Polyhedron, 2000, 19, 185-192.

[12]. Jaworska, J. K. New Platinum(II) Complexes With Schiff Base Ligands. Trans. Met. Chem., 1994, 19, 296-298.

[13]. Tümer, M.; Köksal, H.; Serin, S. Synthesis, Characterization and Thermal Investigation of some Metal Complexes Derived from New Schiff Base Ligands. Synth. React. Inorg. Met.-Org. Chem., 1998, 28 (8), 1393-1404.

[14]. Zolezzi, S.; Decinti, A.; Spodine, E. Sythesis and Characterization of Copper(II) Complexes with Schiff Base Ligands Derived from Ethylenediamine, Diphenylethylenediamine and Nitro, Bromo and Methox Saliclaldehyde. Polyhedron. 1999, 18, 897-904. 